\title{
NEW TESTAMENT FRAGMENTS AT QUMRAN?
}

\author{
By c. J. HEMER
}

The recent publication by J. O'Callaghan of suggested identifications of New Testament texts among the Greek fragments from Cave 7 at Qumran ${ }^{1}$ and the early dates assigned to them on palaeographical grounds will doubtless be rigorously sifted in every facet.

The purpose of the present note is limited to raising one question of method. Some of the fragments are very tiny. Would it be possible to offer alternative identifications of any of them?

I acknowledge the meticulous skill as well as the ingenuity of the restorations, and allow that when one larger fragment has been plausibly attributed to Mark the possibility is raised in other cases. The whole argument will indeed be strengthened if several associated items, each securely and exclusively identified, corroborate each other.

It may however be that when one unexpected and attractive identification has been made it becomes easier in more doubtful cases to find what one is now looking for. But what sort of mathematical chances are there against finding suitable letter sequences in other, even chronologically impossible, texts, and of producing hypothetical 'restorations' to fit them?

I propose to look at $7 \mathrm{Q} 6, \mathrm{I}$ in isolation, defining first, perhaps arbitrarily, the terms of my experiment. I am not here concerned with viable alternatives, but only with a theoretical estimate of the range of possibilities.

The transcription of $7 Q 6,1$ originally offered was:

$$
\begin{aligned}
& ] .[ \\
& ] \in ! \tau . .[ \\
& ] . \lambda \eta \cdot .[
\end{aligned}
$$

$1 \mathrm{~J}$. O'Callaghan, ‘¿Papiros neotestamenticos en la cueva 7 de Qumrän?’ Biblica 53 (1972) 9I-100; $c f$. C. M. Martini, 'Note sui papiri della grotta 7 di Qumrân', ibid., pp. IoI-104. I have had access at Tyndale Library, Cambridge, 
O'Callaghan regards $I T$ in line 2 and $\Lambda H$ in line 3 as completely certain, but uses in his reconstruction conjectural readings of some other letters which appear in the facsimile to be only fractionally preserved. ${ }^{2}$ Their use in reaching a solution may for our purpose be deemed precarious. I shall therefore work experimentally with the two letter groups which look to be substantially legible: $E I T$ and $\Lambda H$. If then only two lines are effectively represented, the number of letters in the lines is only approximately determinable by analogy. The figures for wellfilled lines in the more restorable documents are in the approximate range 20 to 23. The Marcan reading of $7 Q 6$, I is based on a length of about ig letters. We shall then allow possibilities within suitably similar limits.

So the essence of the experiment is to evaluate the chances of finding in any text, irrespective of date, provenance or content; the sequence $E I T$ followed at a distance of about 20 letters by $\Lambda H$, subject only to a plausible manipulation of the lineation to fit the incidence of word and syllable divisions and punctuation spaces.

We may note the natural frequency of these groupings, particularly the first, which is liable to occur freely both within and between words. (a) The sequence EIT has several contexts, e.g. (i) in the second person plural contracted $-\varepsilon i \tau \varepsilon$; (ii) in the third person ending $-\varepsilon \iota+\tau$ - (often an accusative article preceding the object); (iii) in various conjunctions and adverbs

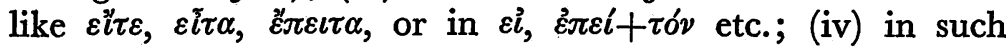
formations as $\pi 0 \lambda(\varepsilon) i \tau \eta s$, $\delta \pi \lambda(\varepsilon) i \tau \eta s$, and numerous ethnics like

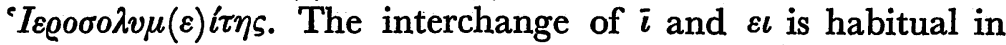
first-century orthography and no special justification of this case is necessary.

(b) $\Lambda H$ is at first sight less promising, and its occurrences less classifiable. Note however (i) in varied inflectional forms

to an unpublished English translation of both articles by W. L. Holladay. The texts were first published in M. Baillet, J. T. Milik, R. de Vaux, Discoveries in the Judaean Desert of Fordan. III Les 'Petites Grottes' de Qumrân, Clarendon Press (Oxford, 1962, p. 145 and Plate XXX.

2 P. 98. He suggests restoring $M k .4: 28$ in the form:

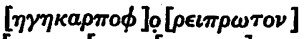

$$
\begin{aligned}
& \text { [ }
\end{aligned}
$$

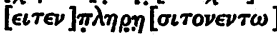

He claims a date near the middle of the first century. 
where the vowel follows a stem ending $-\lambda$, e.g. $\alpha \lambda \lambda \eta, \pi 0 \lambda \lambda \dot{\eta}, \tau \varepsilon^{\prime} \lambda \eta$, $\varphi \iota \lambda \hat{\eta}^{\prime} \sigma \omega, \dot{\alpha} \gamma \gamma \varepsilon \hat{\varepsilon} \lambda \lambda \eta$; (ii) in the stems of such very familiar words as $\dot{\alpha} \lambda \lambda \eta^{\prime} \lambda o v \varsigma, " ~ E \lambda \lambda \eta \nu, \dot{\alpha} \lambda \eta \theta \dot{\eta} \zeta$, and their derivatives.

These patterns may be sought in suitable places. A sampling of the practical injunctions of I Thessalonians 5:I I-28, where (a) (i) recurs, quickly revealed nine instances of sequence (a) and six of (b). In verses I I and 18 both groups occur together, but not separated by sufficient letters to permit reconstruction of a suitable line.

In 2 Thessalonians the case is otherwise. The terms of our experiment are fulfilled twice within the space of a chapter:

2 Thessalonians 2:I5.

$[\alpha \sigma \varepsilon \delta \iota \delta \alpha \chi \theta \eta \tau \varepsilon] \varepsilon \iota \tau[\varepsilon \delta \iota \alpha \lambda o \gamma o v]$

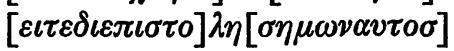

24 letters

24 letters

or, in customary typography:

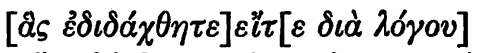

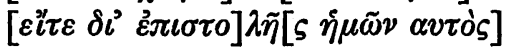

2 Thessalonians 3:14.

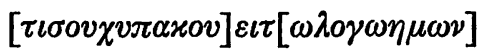

$[\delta\llcorner\alpha \tau \eta \sigma \varepsilon \pi \iota \sigma \tau \sigma] \lambda \eta[\sigma \tau o v \tau o \nu \sigma \eta \mu]$

24 letters

24 letters

or:

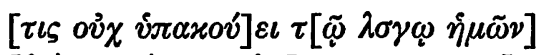

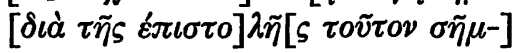

Of course neither of these offers a real alternative. It could doubtless be shown that the doubtful traces of other letters in the fragment would exclude the viability of either of these readings. But the experiment will still serve to make a broader point. The possibility of two such identically arranged reconstructions within so short a passage poses a question. The chances of coincidence are too great. May not any identifications of such brief fragments be open to the objection that alternatives are too easy to come by? It may be too easy to find the answer in Mark if one is seeking it there.

The point may be pressed a little further. If the fragment had indeed been of 2 Thessalonians, the preservation of the whole word $\dot{\varepsilon} \iota \sigma \tau \tau) \lambda \tilde{\eta} s$ would have added nothing to the prospects of choosing between the two possibilities. Where common letter 
sequences are embodied in recurring words, the identification of those words may not help greatly in excluding alternatives: the spacing of two common words on successive lines may not be so much rarer an event than a similar spacing of letter groups. In fact, the case for an essentially two-line fragment, taken in isolation, seems precarious.

This doubt may however throw into stronger relief the more impressive case for the assignment of fragments where clearly legible letters extend over three or four lines. The latitude we have allowed in line length at once becomes restricted: all must fit the same norm. And the mathematical chances against coincidence are multiplied for each additional line. It would be far harder to locate in a text five lines of two clear letters each, but if a place is found it is more likely to be correct. 